\title{
Interaction between Sulfonephthalein Dyes and Chitosan in Aqueous Solution and Its Application to the Determination of Surfactants
}

\author{
Koichi Yamamoto and Kana ADACHI \\ Department of Materials Science, Yonago National College of Technology, 4448, Hikona, Yonago, Tottori \\ 683-8502, Japan
}

\begin{abstract}
A spectrophotometric method for the determination of ionic surfactants with Bromophenol Blue (BPB) based on incorporation into a precipitated chitosan was studied. Cationic surfactants $\left(\mathrm{CS}^{+}\right)$, such as a quaternary ammonium ion containing a long-chain alkyl group, associate with $\mathrm{BPB}^{2-}$ buffered at about $\mathrm{pH} 9$ to form the ion associate $\left(\mathrm{CS}^{+}\right)_{2} \cdot \mathrm{BPB}^{2-}$. $\mathrm{CS}^{+}$associates with anionic surfactants $\left(\mathrm{AS}^{-}\right)$. In the presence of a definite amount of $\mathrm{CS}^{+}$, an increase in the amount of $\mathrm{AS}^{-}$leads to a decrease in the amount of excess $\mathrm{CS}^{+}$, and therefore to a decrease in the amount of the ion associate of $\mathrm{CS}^{+}$ with $\mathrm{BPB}^{2-}$. The addition of a chitosan dissolved in acetic acid to a solution containing these ion associates leads immediately to precipitation of the chitosan and the incorporation of the ion associates $\left(\mathrm{CS}^{+}\right)_{2} \cdot \mathrm{BPB}^{2-}$ or $\mathrm{CS}^{+} \cdot \mathrm{AS}^{-}$into the precipitated chitosan. After centrifuging, ionic surfactants can be determined by the following two methods: (1) the absorbance of the supernatant solution is measured at $590 \mathrm{~nm}$. (2) After the supernatant solution is separated, the precipitate is dissolved in an acetic acid solution and the absorbance is measured at $625 \mathrm{~nm}$. Because the color of the precipitate is judged by the naked eye, this can be applied to the visual method. This is a simple and rapid method for the determination of a $10^{-6} \mathrm{M}$ order of ionic surfactants.
\end{abstract}

(Received February 5, 2003; Accepted June 2, 2003)

\section{Introduction}

Large amounts of synthetic surfactants have been used in industrial and domestic detergents. Most of these surfactants are directly discharged into the environment. Synthetic surfactants sometimes cause water pollution. It is important to determine these surfactants. Almost all of the methods for the spectrophotometric determination of ionic surfactants are based on the formation of ion associates with dyes or metal complex ions and their subsequent extraction into organic solvents such as chloroform, ${ }^{1,2}$ toluene ${ }^{3,4}$ and benzene. ${ }^{5,6}$ These solvents have toxic properties. Several methods for the determination of surfactants without requiring toxic solvents have been developed. Spectrophotometric methods for the determination of ionic surfactants based on the interaction between dyes, such as Bromothymol Blue, ${ }^{7}$ Tetrabromophenolphthalein Ethyl Ester, ${ }^{8}$ Methyl Orange,${ }^{8}$ a phenylazophenol dye, ${ }^{8}$ Bromocresol Purple, ${ }^{9,10}$ Congo Red, ${ }^{11}$ Thymolphthalein, ${ }^{11}$ Rose Bengal ${ }^{12}$ and Phloxine $\mathrm{B},{ }^{12}$ and surfactants, in aqueous solution have been reported. These methods are unsuitable for the determination of trace amounts of surfactants because of low sensitivities. On the other hand, spectrophotometry after the preconcentration of the ion associate of ionic surfactants with dye ions on a flexible polyurethane foam, ${ }^{13,14}$ a polyvinyl chloride sheet, ${ }^{15}$ an organic solvent-soluble membrane filter, ${ }^{16}$ the wall of a PTFE vessel ${ }^{17,18}$ and a filter-paper impregnated with a mixed aluminum-zinc hydroxide, ${ }^{19,20}$ silica gel loaded with ion-pair associates of high molecular weight quaternary ammonium salts and anionic dyes, ${ }^{21}$ have been proposed for the determination of trace amounts of surfactants.
The natural polymer chitin has recently been used for preconcentration $^{22}$ and determination by the spectrophotometric, ${ }^{23,24}$ and atomic absorption spectrometric methods ${ }^{25,26}$ of some metal ions. Trace amounts of ruthenium ${ }^{27}$ and indium ${ }^{28}$ in aqueous solutions were determined by incorporating their metallic elements into a precipitate of chitosan solution in acetic acid from an alkali solution, followed by atomic absorption spectrophotometry. In the present investigation, a simple spectrophotometric method for determining ionic surfactants by incorporating the ion associate of the anionic sulfonephthalein dye with a cationic surfactant into a precipitate of chitosan without a harmful organic solvent was developed.

\section{Experimental}

\section{Apparatus}

A JASCO Uvidec-430 spectrophotometer was used for recording spectra and absorbance measurements in quartz cells of $10 \mathrm{~mm}$ light pathlength. The $\mathrm{pH}$ values were measured with a Hitachi-Horiba (Model F-8 dp) pH-meter.

\section{Reagents and materials}

Bromophenol Blue (BPB), Bromochlorophenol Blue (BCPB), Bromocresol Purple (BCP), Bromocresol Green (BCG) and Bromothymol Blue (BTB) were prepared by dissolving appropriate amounts of dyes in $5 \mathrm{ml}$ of $0.01 \mathrm{M}$ sodium hydroxide and diluting to $200 \mathrm{ml}$ with distilled water. The cationic surfactants $\left(\mathrm{CS}^{+}\right)$were tetradecyltrimethylammonium chloride (TDTMA, $>98 \%$ purity), cetyltrimethylammonium chloride (CTMA, >95\% purity), stearyltrimethylammonium 
chloride (STMA, >97\% purity), cetyldimethylbenzylammonium chloride (CDMBA, >95\% purity) and distearyldimethylammonium chloride (DSDM, >95\% purity) obtained from Tokyo Kasei Co., Ltd., and tetradecyldimethylbenzylammonium chloride (Zephiramine: Zeph, >98\% purity) obtained from Dojindo Laboratories. $\mathrm{CS}^{+}$solutions were prepared from the salts, after drying under reduced pressure. Accurately weighed amounts of the dried salts were dissolved in distilled water to give stock standard solutions, which were diluted before use. The anionic surfactants $\left(\mathrm{AS}^{-}\right)$were sodium laurylsulfate (LS, $>98.2 \%$ purity) and sodium lineardodecylbenzenesulfonate (DBS, >99\% purity) obtained from Wako Pure Chemical Ind. and 1-decanesulfonic acid sodium salt (DS, >98\% purity), 1-dodecanesulfonic acid sodium salt (DDS, >98\% purity), 1-tetradecanesulfonic acid sodium salt (TDS) and 1-hexadecanesulfonic acid sodium salt (HDS) from Tokyo Kasei Co., Ltd. AS $^{-}$solutions were prepared from the salt, after drying under reduced pressure. Accurately weighed amounts of the dried salts were dissolved in distilled water to give stock standard solutions, which were diluted before use. The nonionic surfactant (NS) was poly(oxyethylene)dodecyl ether (HOEDE, $n$ is the number-average degree of polymerization, $n=7,99.9 \%$ purity) obtained from Wako Pure Chemical Ind. An accurately weighed amount of the surfactant was dissolved in distilled water to give a stock solution, which was diluted before use. Ammoniacal buffer solution (1.25 M) was used to adjust the $\mathrm{pH}$ of the solution to 9.2. Chitosans were Type I (degree of deacetylation, 97.5\%; molecular weight, 46600), Type II (degree of deacetylation, >90.0\%; molecular weight, 70600), Type III (chitosan from cuttlefish; degree of deacetylation, >90.0\%; molecular weight, 380000), Type IV (degree of deacetylation, 87.2\%; molecular weight, 1000000) and Type $\mathrm{V}$ (degree of deacetylation, 85.4\%; molecular weight, 2000000) from Yaegaki Hakkou Giken Co., Ltd.. Chitosans were dissolved in a $0.5 \mathrm{M}$ acetic acid solution to give $2(\mathrm{w} / \mathrm{v}) \%$ stock solutions, which were diluted before use. All of the reagents were of analytical-reagent grade and were used as received.

\section{Procedure for the determination of $\mathrm{CS}^{+}$}

First, $17 \mathrm{ml}$ of a sample solution containing less than $1.18 \times$ $10^{-5} \mathrm{M}$ of $\mathrm{CS}^{+}, 1 \mathrm{ml}$ of a $1.25 \mathrm{M}$ ammoniacal buffer solution (pH 9.2), $1 \mathrm{ml}$ of a $2 \times 10^{-4} \mathrm{M}$ BPB solution and $1 \mathrm{ml}$ of a 1 (w/v)\% Type II chitosan solution was taken into a 50-ml centrifuge tube and mixed well. After centrifuging at 4000 r.p.m. for $5 \mathrm{~min}, \mathrm{CS}^{+}$was determined by the following two methods: (1) the absorbance of the supernatant solution was measured at $590 \mathrm{~nm}$. (2) After the supernatant solution was separated, the precipitate was dissolved in $3 \mathrm{ml}$ of a $0.25 \mathrm{M}$ acetic acid solution and the absorbance was measured at 625 $\mathrm{nm}$.

\section{Procedure for the determination of $A S^{-}$}

First, $16 \mathrm{ml}$ of a sample solution containing less than $1.25 \times$ $10^{-5} \mathrm{M}$ of $\mathrm{AS}^{-}, 1 \mathrm{ml}$ of $2 \times 10^{-4} \mathrm{M} \mathrm{DSDM}^{+}$solution, $1 \mathrm{ml}$ of $1.25 \mathrm{M}$ ammoniacal buffer solution ( $\mathrm{pH} 9.2$ ), $1 \mathrm{ml}$ of $2 \times 10^{-4} \mathrm{M}$ BPB solution and $1 \mathrm{ml}$ of 1 (w/v)\% Type II chitosan solution was taken into a 50-ml centrifuge tube and mixed well. After centrifuging at 4000 r.p.m. for 5 min, $\mathrm{AS}^{-}$was determined by the following two methods: (1) the absorbance of the supernatant solution was measured at $590 \mathrm{~nm}$. (2) After the supernatant solution was separated, the precipitate was dissolved in $3 \mathrm{ml}$ of a $0.25 \mathrm{M}$ acetic acid solution, and the absorbance was measured at $625 \mathrm{~nm}$.

\section{Results and Discussion}

Interaction between sulfonephthalein dyes and chitosan in an aqueous solution

The adsorption behaviors of sulfonephthalein dye anions on both chitosan powder and chitosan precipitate. Chitosan was dissolved in a weak acid, such as acetic acid. The dissolved chitosan solution was precipitated by an alkaline solution. The behaviors of the adsorption of sulfonephthalein dyes $\left(\mathrm{H}_{2}\right.$ Dye $)$ on both a chitosan powder and a chitosan precipitate were examined. Both a monovalent dye, anion $\mathrm{HDye}^{-}$(in acidic solution), and a divalent dye, anion Dye ${ }^{2-}$ (in alkaline solution), adsorbed on the chitosan powder, which caused a large value of the reagent blank. It was difficult to determine $\mathrm{CS}^{+}$with the chitosan powder, because there was no difference in the absorbance bet ween the sample and the reagent blank solutions. On the other hand, the ion associates of $\mathrm{CS}^{+}$with $\mathrm{HDye}^{-}$and Dye $^{2-}$ were incorporated into the precipitate of chitosan and Dye $^{2-}$, but were not incorporated into the precipitate of chitosan. It was possible to determine $\mathrm{CS}^{+}$with the precipitate of chitosan, because there was a difference in the absorbance between the sample and the reagent blank solutions. Therefore, the precipitation of chitosan was examined for the determination of $\mathrm{CS}^{+}$.

Metachromasy and absorption spectra. Five sulfonephthalein dyes (BPB, BCPB, BCP, BCG and BTB) were used. Monovalent dye anions produced by controling the $\mathrm{pH}$ of the solution were examined in acidic chitosan solution. The largest changes in the absorbances at the wavelength of the absorption maximum of both monovalent and divalent dye anions in the presence of chitosan were measured under $1.25 \times 10^{-5} \mathrm{M}$ Dye and $0.2(\mathrm{w} / \mathrm{v}) \%$ Type II chitosan: BPB $(-0.163(435 \mathrm{~nm})$, $0.514(588 \mathrm{~nm}))$, BCPB $(-0.129(434 \mathrm{~nm}), 0.446(590 \mathrm{~nm}))$, ВCP $(0.021(427 \mathrm{~nm}), 0.042(585 \mathrm{~nm}))$, ВTB $(-0.015(429 \mathrm{~nm})$, $0.010(616 \mathrm{~nm}))$, BCG $(-0.048(442 \mathrm{~nm}), 0.098(616 \mathrm{~nm}))$. The $\mathrm{BPB}$ and $\mathrm{BCPB}$ solutions changed from yellow to violet in acetic acid, but the colors of the other dyes solutions were hardly changed. For example, in the case of BPB, the addition of a chitosan solution to BPB in an acetic acid solution resulted in a decrease of the absorbance at $435 \mathrm{~nm}$ and an increase in the absorbance at $588 \mathrm{~nm}$, i.e., a color change from yellow to violet, which may have been caused by the dissociation reaction of a proton from the protonated dye $\left(\mathrm{HBPB}^{-}\right.$to $\left.\mathrm{BPB}^{2-}\right)$. These absorption spectral changes are shown in Fig. 1. The metachromasy increased with the increase in the chitosan concentration.

This metachromasy is useful for the sensitive determination of ionic surfactants by method (2), because the molar absorptivity of divalent dye anions are larger than those of monovalent dye anions.

Examination of the procedures for the determination of ionic surfactants

Selection of the sulfonephthalein dye. Five sulfonephthalein dyes were used. For $6 \times 10^{-6} \mathrm{M} \mathrm{Zeph}^{+}\left(\right.$sample I), $1 \times 10^{-5} \mathrm{M}$ $\mathrm{Zeph}^{+}$(sample II) solutions and a blank solution not containing $\mathrm{CS}^{+}$, the examination for the selection of dye was made by method (1). The differences in the absorbance at the wavelength of the absorption maximum between the sample solutions and the blank solution were measured under $1 \times 10^{-5}$ M dye, 0.1 M buffer solution ( $\mathrm{pH} 10.5)$ and 0.1 (w/v)\% Type II chitosan: for sample I, BPB $(-0.041(590 \mathrm{~nm}))$, BCPB $(-0.022(589 \mathrm{~nm}))$, BCP $(0.010(588 \mathrm{~nm}))$, BTB $(-0.012(615 \mathrm{~nm}))$, BCG $(-0.030(615 \mathrm{~nm}))$ and for sample II, BPB $(-0.137(590$ 


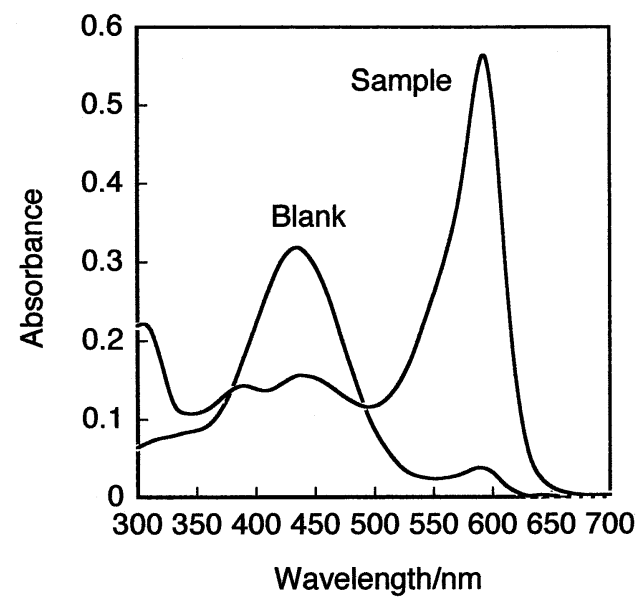

Fig. 1 Absorption spectra of BPB associated with chitosan. $1.25 \times$ $10^{-5} \mathrm{M}$ BPB; $0.2 \mathrm{M}$ acetic acid solution; $0.2(\mathrm{w} / \mathrm{v}) \%$ Type II chitosan.

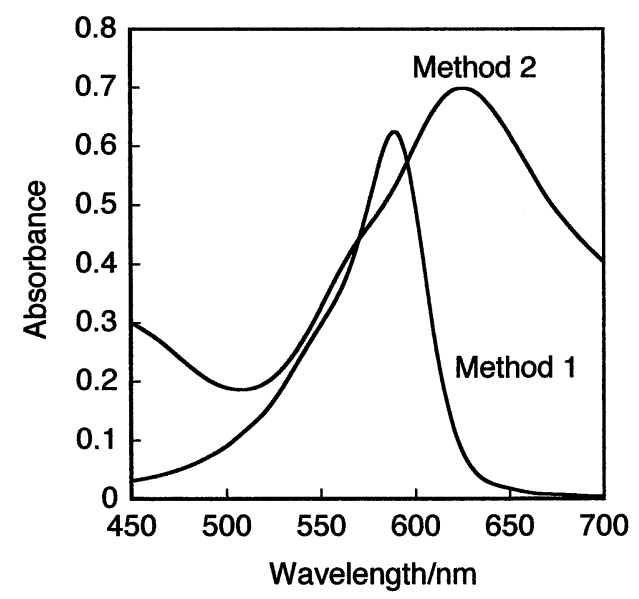

Fig. 2 Absorption spectra of DSDM ${ }^{+}$with BPB in methods (1) and

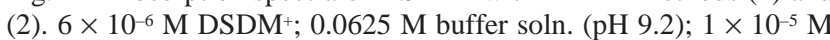
BPB; 0.05 (w/v) \% Type II chitosan.

$\mathrm{nm}))$, ВСРВ $(-0.074(589 \mathrm{~nm}))$, ВCP $(-0.011(588 \mathrm{~nm}))$, ВТВ $(-0.062(615 \mathrm{~nm}))$, BCG $(-0.100(615 \mathrm{~nm}))$. The difference in the absorbance between the sample and the blank solutions was in the order $\mathrm{BPB}>\mathrm{BCG}>\mathrm{BCPB}>\mathrm{BTB}>\mathrm{BCP}$, and its difference was about zero for BCP. Therefore, BPB was used in all subsequent experiments.

The absorption spectra of the $\mathrm{DSDM}^{+}$sample with BPB obtained by methods (1) and (2) are shown in Fig. 2. The absorption maxima for methods (1) and (2) are $590 \mathrm{~nm}$ and 625 $\mathrm{nm}$, respectively. The shift to a longer wavelength $(625 \mathrm{~nm})$ in method (2) was caused by the above metachromasy and the presence of $\mathrm{CS}^{+}$incorporated into the precipitate of chitosan. In subsequent experiments, these wavelengths of the absorption maximum were used to examine the procedures for the determination of ionic surfactants.

Effect of the species of the quaternary ammonium cation. The effect of the species of the quaternary ammonium cation $\left(\mathrm{Q}^{+}\right)$ was examined by method (1). The differences in the absorbance at $590 \mathrm{~nm}$ between the sample solutions and the blank solution were measured under $1 \times 10^{-5} \mathrm{M}$ BPB, $1 \times 10^{-5}$ $\mathrm{M} \mathrm{Q}^{+}, 0.1 \mathrm{M}$ buffer solution $(\mathrm{pH} 10.5)$ and $0.1(\mathrm{w} / \mathrm{v}) \%$ Type II chitosan: TDTMA $^{+}(0)$, CTMA $^{+}(-0.104)$, STMA $^{+}(-0.125)$,

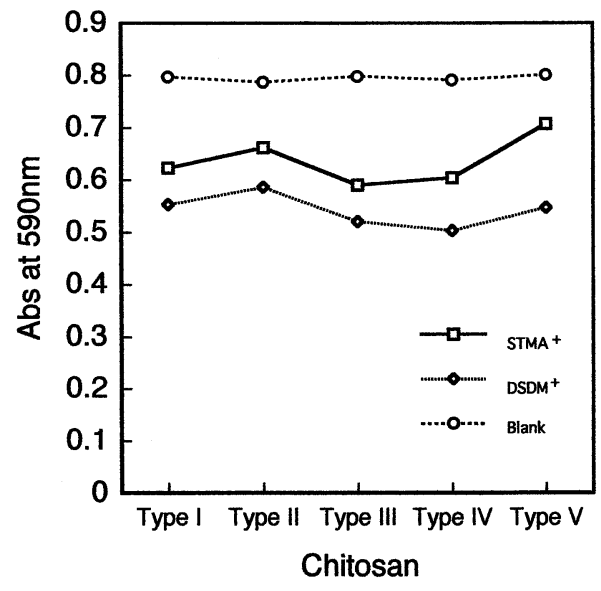

Fig. 3 Effect of the species of chitosan. $1 \times 10^{-5} \mathrm{M} \mathrm{Q}^{+} ; 0.1 \mathrm{M}$ buffer soln. $(\mathrm{pH} 10.5) ; 1 \times 10^{-5} \mathrm{M} \mathrm{BPB} ; 0.1$ (w/v) $\%$ chitosan.

$\mathrm{Zeph}^{+}(-0.137), \mathrm{CDMBA}^{+}(-0.120), \mathrm{DSDM}^{+}(-0.201)$. There was no difference in the absorbance between the sample solution and the blank solution of $\mathrm{TDTMA}^{+}$, which shows that TDTMA $^{+}$does not associate with the BPB dye anion in aqueous solution. On the other hand, there are almost all of the same differences in the absorbance between the sample solutions of $\mathrm{CTMA}^{+}, \mathrm{STMA}^{+}, \mathrm{Zeph}^{+}$and $\mathrm{CDMBA}^{+}$and the blank solution, which shows that almost all of the same degrees of the ion associations of these $\mathrm{Q}^{+}$with the BPB dye anion occurs in an aqueous solution. $\mathrm{DSDM}^{+}$showed the largest difference in the absorbance.

Effect of the species of chitosan. Five chitosans of Type I - V were used. For $\mathrm{STMA}^{+}$, and $\mathrm{DSDM}^{+}$sample solutions and a blank solution not containing $\mathrm{CS}^{+}$, an examination of the selection of chitosan was made by method (1). The result is shown in Fig. 3. For a blank solution, all of the chitosans showed almost the same absorbance. For the STMA ${ }^{+}$solution, there was a small difference in the absorbance between the blank and the sample solutions with Type V chitosan. For the $\mathrm{DSDM}^{+}$solution, there were large differences in the absorbance between the blank and the sample solutions with Type III - V chitosans. Type III and IV chitosans may be suitable for the determination of $\mathrm{CS}^{+}$because, on the whole, these chitosans showed large differences in the absorbance between the blank and sample solutions.

Effect of the $\mathrm{pH}$. The effect of the $\mathrm{pH}$ was examined by varying the $\mathrm{pH}$ of $\mathrm{STMA}^{+}, \mathrm{DSDM}^{+}$and the blank solutions with ammoniacal buffer solutions of $\mathrm{pH} 9.2$ - 11.0 for all chitosans in method (1). The blank solutions showed almost constant absorbances regardless of the $\mathrm{pH}$ of the solution and the species of chitosan. The sample solutions showed the largest difference in the absorbance between the blank and the sample solutions for all chitosans by using an ammoniacal buffer solution of $\mathrm{pH}$ 9.2. At this $\mathrm{pH}$ the effect of the species of chitosan was small. In subsequent experiments, ammoniacal buffer solutions of $\mathrm{pH}$ 9.2 and Type II chitosan were used.

Effect of the concentration of $B P B$. The effect of the concentration of BPB was examined by method (1) in the range of $0.25 \times 10^{-5}-2.0 \times 10^{-5} \mathrm{M}$. $\mathrm{DSDM}^{+}$was used as $\mathrm{Q}^{+}$of the sample solution. The absorbances of the sample and the blank solutions increased with an increase in the concentration of $\mathrm{BPB}$. The increment of the absorbance in the range of a low concentration of BPB was smaller than that in the range of a high concentration of BPB. In subsequent experiments, $1 \times 10^{-5}$ 
Table 1 Calibration curves and coefficients of correlation of cationic surfactants

\begin{tabular}{|c|c|c|c|c|}
\hline \multirow{2}{*}{ Cationic surfactant } & \multirow{2}{*}{ Determination range/M } & \multicolumn{2}{|c|}{ Regression line $(Y=a X+b)^{\mathrm{a}}$} & \multirow{2}{*}{ Coefficient of correlation } \\
\hline & & $a$ & $b$ & \\
\hline \multicolumn{5}{|l|}{ Method (1) } \\
\hline \multirow[t]{2}{*}{ TDTMA } & $(2-10) \times 10^{-6}$ & $-0.002 \times 10^{6}$ & 0.787 & 0.986 \\
\hline & $(2-8) \times 10^{-6}$ & $-0.003 \times 10^{6}$ & 0.789 & 0.998 \\
\hline \multirow[t]{2}{*}{ CTMA } & $(2-10) \times 10^{-6}$ & $-0.017 \times 10^{6}$ & 0.819 & 0.989 \\
\hline & $(4-10) \times 10^{-6}$ & $-0.020 \times 10^{6}$ & 0.839 & 0.999 \\
\hline STMA & $(0.82-10) \times 10^{-6}$ & $-0.022 \times 10^{6}$ & 0.800 & 0.999 \\
\hline \multirow[t]{2}{*}{ Zeph } & $(2-10) \times 10^{-6}$ & $-0.026 \times 10^{6}$ & 0.835 & 0.993 \\
\hline & $(4-10) \times 10^{-6}$ & $-0.029 \times 10^{6}$ & 0.860 & 1.000 \\
\hline \multirow{2}{*}{ CDMBA } & $(0.72-10) \times 10^{-6}$ & $-0.025 \times 10^{6}$ & 0.818 & 0.991 \\
\hline & $(2-10) \times 10^{-6}$ & $-0.028 \times 10^{6}$ & 0.840 & 1.000 \\
\hline DSDM & $(0.58-10) \times 10^{-6}$ & $-0.031 \times 10^{6}$ & 0.809 & 0.997 \\
\hline \multicolumn{5}{|l|}{ Method (2) } \\
\hline \multirow[t]{2}{*}{ TDTMA } & $(4-8) \times 10^{-6}$ & $0.001 \times 10^{6}$ & 0.012 & 0.982 \\
\hline & $(6-10) \times 10^{-6}$ & $0.001 \times 10^{6}$ & 0.007 & 0.982 \\
\hline \multirow[t]{2}{*}{ CTMA } & $(2-8) \times 10^{-6}$ & $0.014 \times 10^{6}$ & -0.014 & 0.979 \\
\hline & $(4-10) \times 10^{-6}$ & $0.022 \times 10^{6}$ & -0.060 & 0.983 \\
\hline \multirow[t]{2}{*}{ STMA } & $(0.32-10) \times 10^{-6}$ & $0.037 \times 10^{6}$ & -0.001 & 0.996 \\
\hline & $(2-10) \times 10^{-6}$ & $0.040 \times 10^{6}$ & -0.021 & 0.999 \\
\hline Zeph & $(4-10) \times 10^{-6}$ & $0.068 \times 10^{6}$ & -0.241 & 0.997 \\
\hline \multirow[t]{2}{*}{ CDMB } & $(0.15-10) \times 10^{-6}$ & $0.079 \times 10^{6}$ & -0.061 & 0.984 \\
\hline & $(2-10) \times 10^{-6}$ & $0.091 \times 10^{6}$ & -0.148 & 0.998 \\
\hline \multirow[t]{2}{*}{ DSDM } & $(0.10-10) \times 10^{-6}$ & $0.126 \times 10^{6}$ & -0.053 & 0.995 \\
\hline & $(2-10) \times 10^{-6}$ & $0.137 \times 10^{6}$ & -0.131 & 0.999 \\
\hline
\end{tabular}

a. The calibration curve for each cationic surfactant was presented as a regression line $\left(Y=a X+b ; Y\right.$ : absorbance at $\lambda_{\max }$ (supernatant, 590 $\mathrm{nm}$; precipitate, $625 \mathrm{~nm}), X$ : concentration $(\mathrm{M}), a$ : proportionality constant, $b$ : intercept).

M BPB was employed.

Effects of the concentrations of chitosan and buffer solution. The effects of the concentrations of the chitosan and the buffer solution were examined by methods (1) and (2) in the ranges of $0.0125-0.05(\mathrm{w} / \mathrm{v}) \%$ and $0.05-0.20 \mathrm{M}$, respectively. For the supernatant solution, the sample and the reagent blank solutions showed almost constant absorbances regardless of the concentrations of the chitosan and the buffer solution. For the dissolved precipitate solution, the reagent blank solutions showed almost constant absorbances regardless of the concentrations of the chitosan and the buffer solution. On the other hand, the absorbance of the sample solution increased with an increase of the concentration of chitosan, and the maximum and constant absorbance of the sample solution was obtained at $0.05-0.075 \mathrm{M}$ of the buffer solution. Therefore, $0.05(\mathrm{w} / \mathrm{v}) \%$ chitosan and $0.0625 \mathrm{M}$ buffer solution were used in subsequent work.

Effect of the concentration of acetic acid for dissolving precipitated chitosan. The effect of the concentration of acetic acid for dissolving the precipitated chitosan in method (2) was examined in the range of $0.1-2.0 \mathrm{M}$. A volume of $3 \mathrm{ml}$ of acetic acid solution was employed for dissolving the precipitated chitosan because its volume was sufficient to measure with an 10-mm absorption cell. The maximum and constant absorbances of the sample solution were obtained at $0.1-0.5 \mathrm{M}$. Therefore, a $0.25 \mathrm{M}$ acetic acid solution was used to dissolve the precipitated chitosan.

\section{Calibration curve, sensitivity and precision}

The absorbances at different concentrations of $\mathrm{CS}^{+}$were measured by the procedure for the determination of $\mathrm{CS}^{+}$. When the absorbance for each $\mathrm{CS}^{+}$was measured by method (1), the absorbance at $590 \mathrm{~nm}$ decreased along with an increase in the concentration of $\mathrm{CS}^{+}$. When the absorbance for each $\mathrm{CS}^{+}$was measured by method (2), the absorbance at $625 \mathrm{~nm}$ increased with an increase of the concentration of $\mathrm{CS}^{+}$. The determination range, the regression line, and the correlation coefficients between the concentrations of $\mathrm{CS}^{+}$and the absorbances by methods (1) and (2) are given in Table 1. The absolute value of the proportionality constant of the regression line is related to the ion-association reaction of $\mathrm{CS}^{+}$with the $\mathrm{BPB}$ anion, that is, the hydrophobic interaction between $\mathrm{CS}^{+}$and $\mathrm{BPB}$ anion. The hydrophobic property of $\mathrm{CS}^{+}$increases with an increase in the number of carbon atoms in $\mathrm{CS}^{+}$, and increases the absolute value of the proportionality constant of the regression line. It seems that it is difficult to determine trace amounts of TDTMA because of a low sensitivity. $\mathrm{CS}^{+}$in the sample solution could be determined at $10^{-6} \mathrm{M}$ level for $20 \mathrm{ml}$ of the sample solution according to the recommended procedure. The correlation coefficients in the straight calibration curves for TDTMA, CTMA, STMA, Zeph, CDMBA and DSDM were 0.979 to 1.000. The relative standard deviations for $8 \times 10^{-6} \mathrm{M}$ Zeph solution $(n=3)$ of the methods (1) and (2) were $1.2 \%$ and $2.1 \%$, respectively.

In the determination of $\mathrm{AS}^{-}$, a definite amount of $\mathrm{CS}^{+}$was added to $\mathrm{AS}^{-}$, and the amount of the ion associate of excess $\mathrm{CS}^{+}$ with divalent $\mathrm{BPB}$ anion incorporated into the precipitate of chitosan was determined. $\mathrm{DSDM}^{+}$was used as $\mathrm{CS}^{+}$. The absorbances at different concentrations of $\mathrm{AS}^{-}$were measured by the procedure for the determination of $\mathrm{AS}^{-}$. When the absorbance for each $\mathrm{AS}^{-}$was measured by method (1), the absorbance at $590 \mathrm{~nm}$ increased with an increase in the concentration of $\mathrm{AS}^{-}$. When the absorbance for each $\mathrm{AS}^{-}$was measured by method (2), the absorbance at $625 \mathrm{~nm}$ decreased with an increase in the concentration of $\mathrm{AS}^{-}$. The determination range, the regression line, and the correlation coefficients between the concentrations of $\mathrm{AS}^{-}$and the absorbances by methods (1) and (2) are shown in Table 2. 
Table 2 Calibration curves and coefficients of correlation of anionic surfactants

\begin{tabular}{|c|c|c|c|c|}
\hline \multirow{2}{*}{ Anionic surfactant } & \multirow{2}{*}{ Determination range/M } & \multicolumn{2}{|c|}{ Regression line $(Y=a X+b)^{\mathrm{a}}$} & \multirow{2}{*}{ Coefficient of correlation } \\
\hline & & $a$ & $b$ & \\
\hline \multicolumn{5}{|l|}{ Method (1) } \\
\hline \multirow[t]{2}{*}{ DS } & $(2-8) \times 10^{-6}$ & $-0.003 \times 10^{6}$ & 0.493 & 0.990 \\
\hline & $(2-6) \times 10^{-6}$ & $-0.003 \times 10^{6}$ & 0.494 & 1.000 \\
\hline DDS & $(0.36-4) \times 10^{-6}$ & $0.058 \times 10^{6}$ & 0.507 & 1.000 \\
\hline \multirow[t]{2}{*}{ TDS } & $(0.70-10) \times 10^{-6}$ & $0.030 \times 10^{6}$ & 0.517 & 0.984 \\
\hline & $(0.62-8) \times 10^{-6}$ & $0.034 \times 10^{6}$ & 0.506 & 0.997 \\
\hline \multirow[t]{2}{*}{ HDS } & $(0.75-10) \times 10^{-6}$ & $0.028 \times 10^{6}$ & 0.518 & 0.986 \\
\hline & $(0.66-8) \times 10^{-6}$ & $0.032 \times 10^{6}$ & 0.508 & 0.997 \\
\hline \multirow[t]{2}{*}{ DBS } & $(0.73-10) \times 10^{-6}$ & $0.029 \times 10^{6}$ & 0.502 & 0.997 \\
\hline & $(0.70-8) \times 10^{-6}$ & $0.030 \times 10^{6}$ & 0.498 & 0.999 \\
\hline \multirow[t]{2}{*}{ LS } & $(0.68-10) \times 10^{-6}$ & $0.031 \times 10^{6}$ & 0.497 & 0.977 \\
\hline & $(0.59-8) \times 10^{-6}$ & $0.036 \times 10^{6}$ & 0.484 & 0.992 \\
\hline \multicolumn{5}{|l|}{ Method (2) } \\
\hline \multirow[t]{2}{*}{ DS } & $(0.94-4) \times 10^{-6}$ & $-0.023 \times 10^{6}$ & 1.288 & 0.999 \\
\hline & $(6-10) \times 10^{-6}$ & $-0.010 \times 10^{6}$ & 1.314 & 1.000 \\
\hline DDS & $(0.09-4) \times 10^{-6}$ & $-0.243 \times 10^{6}$ & 1.252 & 0.999 \\
\hline \multirow[t]{2}{*}{ TDS } & $(0.17-10) \times 10^{-6}$ & $-0.125 \times 10^{6}$ & 1.157 & 0.975 \\
\hline & $(0.15-8) \times 10^{-6}$ & $-0.147 \times 10^{6}$ & 1.215 & 0.992 \\
\hline \multirow[t]{2}{*}{ HDS } & $(0.18-10) \times 10^{-6}$ & $-0.122 \times 10^{6}$ & 1.191 & 0.987 \\
\hline & $(0.16-8) \times 10^{-6}$ & $-0.139 \times 10^{6}$ & 1.234 & 0.998 \\
\hline \multirow[t]{2}{*}{ DBS } & $(0.20-10) \times 10^{-6}$ & $-0.106 \times 10^{6}$ & 1.232 & 0.995 \\
\hline & $(0.19-8) \times 10^{-6}$ & $-0.114 \times 10^{6}$ & 1.254 & 0.998 \\
\hline \multirow[t]{2}{*}{ LS } & $(0.18-10) \times 10^{-6}$ & $-0.121 \times 10^{6}$ & 1.162 & 0.976 \\
\hline & $(0.15-8) \times 10^{-6}$ & $-0.142 \times 10^{6}$ & 1.220 & 0.996 \\
\hline
\end{tabular}

a. The calibration curve for each anionic surfactant was presented as a regression line $\left(Y=a X+b ; Y\right.$ : absorbance at $\lambda_{\max }$ (supernatant, 590 $\mathrm{nm}$; precipitate, $625 \mathrm{~nm}), X$ : concentration (M), $a$ : proportionality constant, $b$ : intercept).

Table 3 Effect of co-existing substances on the determination of ionic surfactants

\begin{tabular}{|c|c|c|c|c|c|}
\hline \multirow{3}{*}{ Substance } & \multirow{4}{*}{$\begin{array}{l}\text { Added as } \\
\text { Cationic surfactant }\end{array}$} & \multicolumn{4}{|c|}{ Tolerable concentration $/ \mathrm{M}$} \\
\hline & & \multicolumn{2}{|c|}{ Method (1) } & \multicolumn{2}{|c|}{ Method (2) } \\
\hline & & $8 \times 10^{-6} \mathrm{M}$ Zeph & $8 \times 10^{-6}$ M STMA & $8 \times 10^{-6} \mathrm{M}$ Zeph & $8 \times 10^{-6}$ M STMA \\
\hline HOEDE & & $3.04 \times 10^{-5}$ & $2.02 \times 10^{-5}$ & $3.04 \times 10^{-5}$ & $1.01 \times 10^{-5}$ \\
\hline $\mathrm{Ca}^{2+}$ & $\mathrm{CaCl}_{2}$ & $1.00 \times 10^{-3}$ & $1.00 \times 10^{-3}$ & $5.00 \times 10^{-4}$ & $1.00 \times 10^{-3}$ \\
\hline $\mathrm{Mg}^{2+}$ & $\mathrm{MgSO}_{4}$ & $5.00 \times 10^{-4}$ & $5.00 \times 10^{-4}$ & $2.50 \times 10^{-4}$ & $3.75 \times 10^{-4}$ \\
\hline $\mathrm{Na}^{+}$ & $\mathrm{NaCl}$ & $1.20 \times 10^{-3}$ & $1.20 \times 10^{-3}$ & $3.00 \times 10^{-4}$ & $9.00 \times 10^{-4}$ \\
\hline $\mathrm{K}^{+}$ & $\mathrm{KCl}$ & $1.20 \times 10^{-4}$ & $1.20 \times 10^{-4}$ & $9.00 \times 10^{-5}$ & $1.20 \times 10^{-4}$ \\
\hline $\mathrm{HCO}_{3}^{-}$ & $\mathrm{NaHCO}_{3}$ & $2.00 \times 10^{-3}$ & $2.00 \times 10^{-3}$ & $2.00 \times 10^{-3}$ & $2.00 \times 10^{-3}$ \\
\hline & Anionic surfactant & $4 \times 10^{-6} \mathrm{M} \mathrm{LS}$ & $4 \times 10^{-6} \mathrm{M}$ DBS & $4 \times 10^{-6} \mathrm{M} \mathrm{LS}$ & $4 \times 10^{-6} \mathrm{M}$ DBS \\
\hline Zeph & & $1.00 \times 10^{-6}$ & $2.00 \times 10^{-6}$ & - & $2.00 \times 10^{-6}$ \\
\hline HOEDE & & $3.04 \times 10^{-5}$ & $1.01 \times 10^{-5}$ & $2.02 \times 10^{-5}$ & $1.01 \times 10^{-5}$ \\
\hline $\mathrm{Ca}^{2+}$ & $\mathrm{CaCl}_{2}$ & $1.00 \times 10^{-3}$ & $1.00 \times 10^{-3}$ & $1.00 \times 10^{-3}$ & $1.00 \times 10^{-3}$ \\
\hline $\mathrm{Mg}^{2+}$ & $\mathrm{MgSO}_{4}$ & $5.00 \times 10^{-4}$ & $5.00 \times 10^{-4}$ & $3.75 \times 10^{-4}$ & $5.00 \times 10^{-4}$ \\
\hline $\mathrm{Na}^{+}$ & $\mathrm{NaCl}$ & $1.20 \times 10^{-3}$ & $1.20 \times 10^{-3}$ & $1.20 \times 10^{-3}$ & $9.00 \times 10^{-4}$ \\
\hline $\mathrm{K}^{+}$ & $\mathrm{KCl}$ & $1.20 \times 10^{-4}$ & $1.20 \times 10^{-4}$ & $9.00 \times 10^{-5}$ & $9.00 \times 10^{-5}$ \\
\hline $\mathrm{HCO}_{3}^{-}$ & $\mathrm{NaHCO}_{3}$ & $2.00 \times 10^{-3}$ & $2.00 \times 10^{-3}$ & $2.00 \times 10^{-3}$ & $2.00 \times 10^{-3}$ \\
\hline
\end{tabular}

a. Concentrations giving within $\pm 5 \%$ error in the recovery of ionic surfactants.

The absorbances at different concentrations of $\mathrm{AS}^{-}$were measured. It seems that it is difficult to determine trace amounts of DS because of a low sensitivity. $\mathrm{AS}^{-}$in the sample solution could be determined at the $10^{-6} \mathrm{M}$ level according to the recommended procedure. The correlation coefficients in the straight calibration curves for DS, DDS, TDS, HDS, DBS and LS were 0.975 to 1.000 . The relative standard deviations for a 4 $\times 10^{-6} \mathrm{M} \mathrm{LS}^{-}$solution $(n=3)$ of methods (1) and (2) were $0.4 \%$ and $0.8 \%$, respectively.

\section{Effect of co-existing substances}

The effects of co-existing substances on the determination of $8 \times 10^{-6} \mathrm{M} \mathrm{Zeph}^{+}$and $\mathrm{STMA}^{+}$as the cationic surfactant and $4 \times$ $10^{-6} \mathrm{M} \mathrm{LS}^{-}$and $\mathrm{DBS}^{-}$as the anionic surfactant in $20 \mathrm{ml}$ of the sample solution were investigated by methods (1) and (2). The concentrations of co-existing substances which give the relative error of within about $\pm 5 \%$ in the recovery of each ionic surfactant are given in Table 3. The anionic surfactant, LS', causes interference in the determination of $\mathrm{CS}^{+}$: for $8 \times 10^{-6} \mathrm{M}$ 
Table 4 Determination of ionic surfactants in commercial samples

\begin{tabular}{cccc}
\hline Sample $^{\mathrm{a}}$ & JIS method $^{\mathrm{b}, \mathrm{c}}$ & Proposed method $^{\mathrm{c}}$ & Recovery $^{\mathrm{d}}$ \\
\hline Sample 1(cationic surfactant) & $1.43 \pm 0.02 \%$ & $0.86 \pm 0.05 \%$ & $28.5 \pm 0.7 \%$ \\
Sample 2(anionic surfactant) & $29.4 \pm 0.0 \%$ & $21.0 \pm 0.5 \%$ & $102 \%\left(4 \times 10^{-6} \mathrm{M}\right)$ \\
Sample 3(anionic surfactant) & $19.3 \pm 0.2 \%$ & $105 \%\left(4 \times 10^{-6} \mathrm{M}\right)$ \\
\hline
\end{tabular}

a. Sample 1, rinsing liquid for washing hair; samples 2 and 3, synthetic detergents for washing. The surfactant in sample 1 is stearyltrimethylammonium chloride. The total content of the surfactants in sample 2 is $41 \%$ and the surfactanta are sodium linearalkylbenzenesulfonate, sodium alkyl sulfate and alkylpolyoxyetylene ether. The total content of the surfactants in sample 3 is $32 \%$ and the surfactants are sodium linear-alkylbenzenesulfonate, sodium $\alpha$-sulfocarboxylic ester and sodium carboxylate. b. JIS method: Epton method. c. Mean value \pm standard deviation (three measurements). d. These values were determined by assuming that anionic surfactants in the samples were LS.

$\mathrm{Zeph}^{+}, 2 \times 10^{-6} \mathrm{M} \mathrm{LS}^{-}$causes $+7.4 \%$ and $-29.6 \%$ error in methods (1) and (2), respectively; for $8 \times 10^{-6} \mathrm{M} \mathrm{STMA}^{+}, 2 \times$ $10^{-6} \mathrm{M} \mathrm{LS}^{-}$causes $+9.3 \%$ and $-31.3 \%$ error in methods (1) and (2), respectively. The cationic surfactant, $\mathrm{Zeph}^{+}$, causes interference in the determination of $\mathrm{LS}^{-}$: for $4 \times 10^{-6} \mathrm{M} \mathrm{LS}^{-}, 1 \times$ $10^{-6} \mathrm{M} \mathrm{Zeph}^{+}$causes $+6.6 \%$ error in method (2). The moderate concentrations of $\mathrm{Ca}^{2+}, \mathrm{Mg}^{2+}, \mathrm{Na}^{+}, \mathrm{K}^{+}$and $\mathrm{HCO}_{3}^{-}$do not interfere.

The interferences of other co-existing ionic surfactants in the determination of cationic and anionic surfactants may be avoided by passing the sample through a column packed with an ionic-exchange resin.

\section{Application to commercial samples}

The proposed method was applied to the determination of a cationic surfactant in a commercial rinsing solution for hair, and anionic surfactants in commercial detergents for washing. Table 4 gives the results for the original samples and for the recovery of known quantities of surfactants added to the sample. The results agree approximately with those of the JIS titration method (Epton method). The recovery of the added surfactants was nearly quantitative.

\section{References}

1. "Testing Methods for Industrial Wastewater, Japanese Industrial Standard K 0102", 1993, Japanese Industrial Standards Committee, Japanese Standards Association, Tokyo.

2. Standard methods for the examination of water and waste water, 17th ed., 1989, American Public Health Association, American Water Works Association and Water Pollution Control Federation, Washington, D.C., 5 - 59.

3. S. Motomizu, S. Fujiwara, A. Fujiwara, and K.Toei, Anal. Chem., 1982, 54, 392.

4. K. Yamamoto and S. Motomizu, Analyst [London], 1987, $112,1405$.

5. S. Taguchi and K. Goto, Talanta, 1980, 27, 289.

6. S. Taguchi, I. Kasahara, Y. Fukushima, and K. Goto, Talanta, 1981, 28, 616.

7. S. Z. El-Khateeb and E. M. Abdel-Moety, Talanta, 1988, 35,813 .

8. Y. Gao and S. Motomizu, Bunseki Kagaku, 1996, 45, 1065.
9. K. Yamamoto, K.Ikehara, and S.Motomizu, Bunseki Kagaku, 1990, 39, 393.

10. K. Yamamoto and S. Motomizu, Anal. Chim. Acta, 1991, 246, 333.

11. K. Yamamoto and T. Iwata, Abstracts of 46th Annual Meeting of the Japan Society for Analytical Chemistry, Tokyo, October 1997, 93.

12. K. Yamamoto and M. Kadono, Bunseki Kagaku, 1999, 48, 87.

13. T. Tanaka, K. Hiiro, and A. Kawahara, Bunseki Kagaku, 1973, 22, 523.

14. M. Zenki, T. Yoshida, M. Ohiwane, and M. Nakamura, Bunseki Kagaku, 2001, 50, 345.

15. T. Tanaka, K. Hiiro, and A. Kawahara, Bunseki Kagaku, 1974, 23, 650.

16. Y. Chen, S. Y. Wang, R. F. Wu, D. Y. Qi, and T. Z. Zhou. Anal. Lett., 1998, 31, 691.

17. M. Kamaya, Y. Kaneko, and K. Nagashima, Anal. Chim. Acta, 1999, 384, 215.

18. M. Kamaya, Y. Tomizawa, and K. Nagashima, Anal. Chim. Acta, 1998, 362, 157.

19. P. MacCarthy, R. W. Klusman, S. W. Cowling, and J. A. Rice, Anal. Chem., 1993, 65, 244R.

20. F. Ishino and M. Munemori, Nippon Kagaku Kaishi, 1990, 1360.

21. O. A. Zaporozhets, O. Yu. Nadzhafova, V. V. Verba, S. A. Dolenko, T. Ye Keda, and V. V. Sukhan, Analyst[London], 1998, 123, 1583.

22. K. Komori, S. Igarashi, and T. Yotsuyanagi, Bunseki Kagaku, 1986, 35, 890.

23. S. Hoshi, Y. Kamada, S. Inoue, and M. Matsubara, Anal. Sci., 1988, 4, 227.

24. S. Hoshi, M. Yamada, S. Inoue, and M. Matsubara, Talanta, 1989, 36, 606.

25. H. Minamisawa, T. Hokazono, N. Arai, and T. Okutani, Nippon Kagaku Kaishi, 1993, 937.

26. H. Minamisawa, N. Arai, Y. Tatehaba, and T. Okutani, Nippon Kagaku Kaishi, 1995, 512.

27. H. Minamisawa, H. Kuroki, N. Arai, and T. Okutani, Abstracts of 47th Annual Meeting of the Japan Society for Analytical Chemistry, Tokyo, October 1998, 93.

28. H. Minamisawa, K. Murashima, N. Arai, and T. Okutani, Abstracts of 48th Annual Meeting of the Japan Society for Analytical Chemistry, Tokyo, September 1999, 245. 